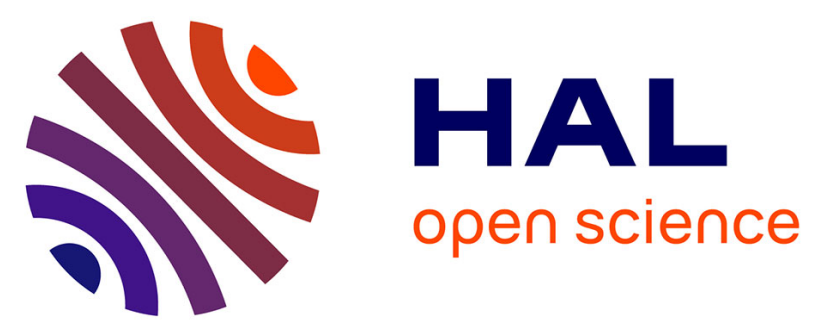

\title{
Numerical and experimental comparison of tracer particle and averaging techniques for particle velocities in a fluidized bed
}

Yupeng Xu, Tingwen Li, Liqiang Lu, Sina Tebianian, Jamal Chaouki, Thomas Leadbeater, Rouzben Jafari, David J Parker, Jonathan Seville, Naoko Ellis, et al.

\section{To cite this version:}

Yupeng Xu, Tingwen Li, Liqiang Lu, Sina Tebianian, Jamal Chaouki, et al.. Numerical and experimental comparison of tracer particle and averaging techniques for particle velocities in a fluidized bed. Chemical Engineering Science, 2019, 195, pp.356-366. 10.1016/j.ces.2018.09.034 . hal-02008311

\section{HAL Id: hal-02008311 \\ https://hal-ifp.archives-ouvertes.fr/hal-02008311}

Submitted on 13 Feb 2019

HAL is a multi-disciplinary open access archive for the deposit and dissemination of scientific research documents, whether they are published or not. The documents may come from teaching and research institutions in France or abroad, or from public or private research centers.
L'archive ouverte pluridisciplinaire HAL, est destinée au dépôt et à la diffusion de documents scientifiques de niveau recherche, publiés ou non, émanant des établissements d'enseignement et de recherche français ou étrangers, des laboratoires publics ou privés. 


\title{
Numerical and experimental comparison of tracer particle and averaging techniques for particle velocities in a fluidized bed
}

\author{
Yupeng $\mathrm{Xu}^{1,8}$, Tingwen $\mathrm{Li}^{1,6^{*}}$, Liqiang $\mathrm{Lu}^{1}$, Sina Tebianian ${ }^{2}$, Jamal Chaouki ${ }^{3}$, Thomas W. \\ Leadbeater ${ }^{7}$, Rouzben Jafari ${ }^{3}$, David J. Parker ${ }^{4}$, Jonathan Seville ${ }^{4}$, Naoko Ellis ${ }^{5}$, John R. \\ Grace $^{5}$ \\ ${ }^{1}$ National Energy Technology Laboratory, U.S. Department of Energy, Morgantown, WV, USA \\ ${ }^{2}$ IFP Energies Nouvelles, Process Design and Modeling division, Lyon, France \\ ${ }^{3}$ Département de génie chimique, Ecole Polytechnique, Montréal, QC Canada H3T 1 J4. \\ ${ }^{4}$ Positron Imaging Centre, University of Birmingham, Birmingham, B15 2TT, UK \\ ${ }^{5}$ Department of Chemical \& Biological Engineering, University of British Columbia, Vancouver, Canada \\ V6T1Z3 \\ ${ }^{6}$ AECOM, Morgantown, WV 26505, United States \\ ${ }^{7}$ Department of Physics, University of Cape Town, South Africa \\ ${ }^{8}$ West Virginia University Research Corporation, Morgantown, WV 26506, USA \\ *Corresponding author: litingwen@gmail.com, tingwen.li@sabic.com
}

\begin{abstract}
Particle tracking methods using emitted radiation are attractive for following motion in opaque systems such as granular materials. Leading examples are Positron Emission Particle Tracking (PEPT) and Radioactive Particle Tracking (RPT). The application of such techniques sometimes requires the use of tracer particles which differ in size, density and/or shape from the particles of interest. This study investigates the extent to which such differences affect the result of the study by using the open source MFIXDEM software to model particle motion in the travelling fluidized bed experiments. The results are compared with previously reported experimental studies using both PEPT and RPT. Consistent numerical results were obtained for both PEPT and RPT tracer particles. In determining averaged velocities using such techniques, there is a choice to be made between averaging velocities of particles crossing a virtual plane over a period of time (the "face-average" approach) or those passing through a defined volume over time (the "volume-average" approach). The differences between results obtained with these two approaches are shown to be significant in this case, for both computation and experiment.
\end{abstract}

Keywords: fluidized bed, particle tracking, particle velocity, numerical simulation

\section{Introduction}

Multiphase reactors are important in many chemical processes. The ability to design and operate these reactors safely and efficiently depends, among other factors, on being able to characterize and predict their flow patterns. This requires that there should be accurate methods of measuring key hydrodynamic quantities such as phase hold-ups, solids fluxes and particle velocities. 
Gas-solid fluidized beds are subject to complex hydrodynamics, with major challenges to measure such quantities as particle velocity and void fraction, due to such factors as the opaque and abrasive nature of the solid particles, turbulence, and multiple scales of motion and flow structure. Among the techniques for determining such properties are particle tracking procedures, where the trajectory of a single representative and detectable tracer particle is followed over prolonged periods of time, long enough that averaging yields good estimates of time-average particle velocity and local volume fraction occupied by particles (Patience and Chaouki, 1993; Chaouki et al., 1997; Leadbeater et al., 2012).

In order to compare and evaluate alternative measurement techniques, a collaborative multi-institutional project was undertaken by researchers in Canada, the United Kingdom and the U.S.A. to measure important hydrodynamic properties of a unique gas-fluidized bed utilizing alternative experimental techniques. In order to compare these experimental techniques and, at the same time, generate a unique and comprehensive data base for testing the validity of computational and other predictive models, a "travelling fluidized bed" was designed and constructed which could operate under identical conditions in different laboratories (Dubrawski et al., 2013; Tebianian et al., 2015a, 2015b, 2016a, 2016b). Each of these laboratories was equipped with special instrumentation, able to determine local voidages, particle velocities or both. Two of the experimental techniques deployed involved particle tracking, in one case based on radioactive particle tracking (RPT) at the Ecole Polytechnique in Montreal, Canada and, in the other, Positron Emission Particle Tracking (PEPT) at the University of Birmingham in the UK. Other characterization techniques included Capacitance Tomography, X-ray Tomography and several Optical Probe configurations, in addition to pressure measurements and X-ray observations.

In general, the different measurement techniques provided qualitative results and trends that were consistent across the spectrum of the different experimental methods. However, there were significant quantitative differences among the measurements obtained under identical experimental conditions. One might expect that the two tracking techniques would, in particular, give similar results for measurements obtained under identical conditions (same equipment, same bed materials, and identical operating conditions.) Surprisingly, however, the deviations between the RPT and PEPT results turned out to be similar to those among the other techniques. An obvious possible explanation for this finding was that the tracer particles used in the two tracking studies differed, not only from each other in terms of density, size, and shape, but also with respect to the bulk properties of the sand or FCC particles which made up the fluidized beds whose properties were being monitored.

For practical reasons, it is sometimes impossible to find tracer particles which closely match the physical properties of the bulk particles in multi-phase flow systems. One objective of this paper is to shed light on the question of whether or not the differences in the properties of the tracer particle are sufficient to account for the difference in hydrodynamic properties recorded in the travelling fluidized bed. The results are also relevant to the broader question of how similar tracer particles must be to the properties 
of bulk particles in order to portray the hydrodynamics accurately. To address these questions, Computational fluid dynamic (CFD) simulations were carried out to predict how single particles with the properties of the actual tracer particles utilized in the RPT and PEPT fluidized bed experiments matched each other and time-average properties of the bulk particles for the reported experimental work.

Another issue addressed in this paper is the difference between alternative procedures for calculating average velocities of particles in fluidized beds and other complex systems. As noted by Tebianian et al. (2015), one option, "face averaging", is to measure, over a time period of sufficient duration to allow statistically sufficient data to be recorded, velocities of the tracer particle as it crosses the plane of interest. An alternative method, called "volume averaging", is to determine the average velocities of the tracer particle only when it is found to occupy a given volume of interest during each time interval. Since slower-moving particles statistically spend longer (or are found with greater frequency) in a given volume element than particles whose velocity are higher, the latter procedure tends to give significantly lower average particle velocities than the former.

\section{Modeling Approach}

In this study, the Multiphase Flow with Interphase eXchanges (MFIX) code, freely available from the U.S. Department of Energy (DOE), National Energy Technology Laboratory (NETL) at https://mfix.netl.doe.gov, was used to predict the motion of the bulk and tracer particles. Specifically, the MFIX-DEM solver, which couples an Eulerian fluid model for the gas with a Lagrangian discrete element model (DEM) for the solid phase, was employed, with the coarse-grain technique adopted for speedup.

\subsection{Fluid governing equations}

In MFIX-DEM, the gas phase flow field is computed from the volume-averaged NavierStokes equations, given (Syamlal et al., 1993) by

$$
\begin{gathered}
\frac{\partial}{\partial t}\left(\varepsilon_{g} \rho_{g}\right)+\nabla \cdot\left(\varepsilon_{g} \rho_{g} \mathbf{u}_{g}\right)=0 \\
\frac{\partial}{\partial t}\left(\varepsilon_{g} \rho_{g} \mathbf{u}_{g}\right)+\nabla \cdot\left(\varepsilon_{g} \rho_{g} \mathbf{u}_{g} \mathbf{u}_{g}\right)=-\varepsilon_{g} \nabla P_{g}-\nabla \cdot\left(\varepsilon_{g} \tau_{g}\right)-\mathbf{S}_{p}+\varepsilon_{g} \rho_{g} \boldsymbol{g}
\end{gathered}
$$

where $\varepsilon_{g}$ is the local gas volume fraction, $\rho_{g}$ the gas phase density, $\mathbf{u}_{g}$ the gas velocity, $P_{g}$ the gas pressure, $\tau_{g}$ the viscous stress tensor, $\boldsymbol{g}$ the gravitational acceleration, and $\mathbf{S}_{p}$ is a source term that accounts for momentum exchange with the solid particles. The inter-phase momentum transfer term on a computational cell can be calculated as

$\mathrm{S}_{p}=\frac{1}{V} \sum_{i=1}^{N_{p}} \frac{1}{6} \pi d_{\mathrm{p}}^{3} W_{p}\left(\nabla P_{\mathrm{f}}\left(\mathbf{x}^{i}\right)+\frac{\beta^{i}}{1-\varepsilon_{\mathrm{f}}}\left(\mathbf{v}_{\mathrm{f}}\left(\mathbf{x}^{i}\right)-\mathbf{v}_{\mathrm{p}}^{i}\right)\right) K\left(\mathbf{x}^{i}, \mathbf{x}_{c}\right)$ 
where $V$ is the volume of a computational cell and $N_{p}$ is the number of particles counted in this cell. $W_{\mathrm{p}}$ is the statistical weight of particles $p, \beta$ is the drag coefficient of particle $i$ in this cell. $\mathbf{v}_{\mathrm{f}}\left(\mathbf{x}^{i}\right)$ is the fluid velocity interpolated at particle $i$, and $K$ is the interpolation weight of particle $i$ to cell $c$.

The gas density is determined using the ideal gas law. The viscous stress tensor is assumed to obey the general form for a Newtonian fluid:

$$
\tau_{g}=-\left[\left(\lambda_{g}-\frac{2}{3} \mu_{g}\right)\left(\nabla \cdot \mathbf{u}_{g}\right) \mathbf{I}+\mu_{g}\left(\left(\nabla \mathbf{u}_{g}\right)+\left(\nabla \mathbf{u}_{g}\right)^{T}\right]\right.
$$

Note that no turbulence model was enabled since the turbulence is usually suppressed in a dense fluidized bed due to the high volume-fraction of solid particles (Elghobashi, 1994, 2006; van der Hoef et al., 2006; Alobaid and Epple, 2013).

\subsection{Equations for particle motion}

For the solid phase, the discrete element method (DEM) was used in which the solid motion is tracked by solving Newton's second law for each individual particle. The interparticle collisions were directly resolved using a soft-sphere model based on a linear spring-dashpot model which treats collisions as a continuous process taking place over a finite time (Cundall and Strack 1979). The contact force was then calculated as a function of the distance between colliding particles, based on physically realistic interaction laws, and using an empirical linear spring stiffness, a dissipation constant and a friction coefficient. The particle-wall interaction was treated in the same way as particle-particle collisions. The coupling between gas and solid phases was through the volume fraction and interphase interaction, i.e. drag force. The coupled CFD-DEM simulation provides particle-scale details on the solid motions and flow structures. Hence, it is very popular for the study of particulate multiphase flows.

The major drawback of CFD-DEM is the high computational cost for tracking each individual particle in a large-scale system, usually consisting of billions, or even trillions, of small particles. To overcome the expensive computational cost of simulating such large numbers of particles, the coarse-grained particle method (Sakai et al. 2014; Lu et al. 2017) was employed in the current study. In coarse-grained CFD-DEM, a number of real particles are lumped into a numerical parcel to reduce the computational cost. The momentum equation for any real particle in a numerical parcel takes the familiar form of Newton's second law of motion:

$m_{\mathrm{p}} \frac{d \mathbf{v}_{\mathrm{p}}}{d t}=m_{\mathrm{p}} \mathbf{g}-\frac{\pi}{6} d_{p}^{3} \nabla P_{f}+\frac{\beta\left(\mathbf{v}_{\mathrm{f}}\left(\mathbf{x}^{i}\right)-\mathbf{v}_{\mathrm{p}}\right)}{1-\varepsilon_{f}} \frac{\pi}{6} d_{p}^{3}+\mathbf{F}_{\mathrm{c}}$

where $m_{\mathrm{p}}$ is the mass of the real particle and $d_{\mathrm{p}}$ is its diameter. On the right-hand side, the forces considered include, in order, gravity, pressure gradient, drag, and contact $\left(\mathbf{F}_{\mathrm{c}}\right)$ forces. The first three of these terms are calculated following the same process as in traditional CFD-DEM (i.e. these forces are based on a real particle). The contact force is calculated by the discrete element method (DEM) in normal $\left(\mathbf{F}^{\mathrm{n}}\right)$ and tangential $\left(\mathbf{F}^{\mathrm{t}}\right)$ directions for the large numerical parcel with a diameter of $d_{\mathrm{CGP}}$ and a coarse-grain size 
ratio of $n=d_{\mathrm{CGP}} / d_{\mathrm{p}}$. The contact force is then divided by the number of real particles in the parcel

$\mathbf{F}_{\mathrm{c}}=\sum_{j=1, j \neq i}^{N}\left(\mathbf{F}_{i j}^{\mathrm{n}}+\mathbf{F}_{i j}^{\mathrm{t}}\right) / n^{3}$

For the particle rotation, the moment of inertia, $I$, is calculated by $m_{\mathrm{p}} d_{\mathrm{p}}{ }^{2} / 10$, and is $n^{5}$ times smaller than the inertia based on the coarse-grained particle. Thus, the torque, $\mathbf{T}$, on each real particle is calculated as:

$\mathbf{T}=\sum_{j=1, j \neq i}^{N}\left(L \mathbf{n} \times \mathbf{F}_{i j}^{t}\right) / n^{5}$

where $L$ is the distance from the numerical particle center to the contact point. More information on the coarse-grain particle method is available (Lu et al., 2014, 2016). Full details on the governing equations, together with the numerical implementation and coupling procedure, can also be found (Garg et al., 2012; Li et al., 2012; Xu et al., 2013, 2014, 2017a, 2017b, 2017c).

As discussed in the next section, it is important in the current study to simulate the full particle size distribution (PSD) of the bed material and account for the detailed physical properties of the tracer particles. It is straight-forward to incorporate an arbitrary distribution of particle properties, like size and density, in DEM simulations. Two approaches possible to account for the full PSD in the current coarse-grain DEM simulation were implemented, as shown in Figure 1. In the first approach, a constant coarse-grain size ratio is used for all the particles, and the shape of the PSD of the coarsegrained parcels remains identical to that of the original powder, with a shift to the coarser side. In the second approach, different statistical weights are used for particles of different diameters, and the original poly-disperse powder is scaled to a coarse monodisperse system with the same parcel size. Lu et al. (2018) compared these two types of coarse-graining methods for a poly-disperse system. The second approach was found to be slightly less accurate, but it provided higher computational efficiency compared to the first approach, which is more straight-forward.

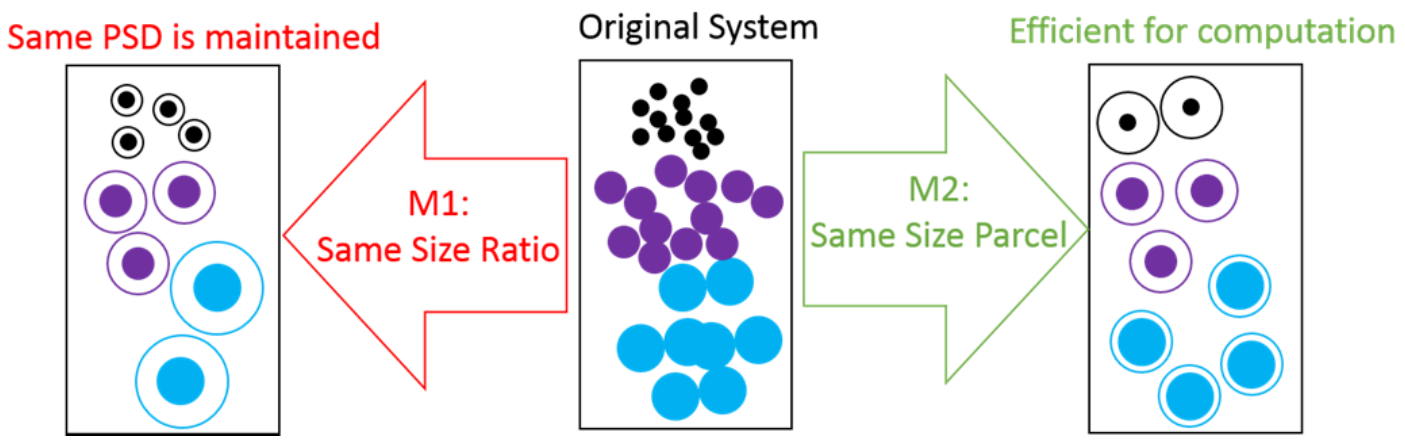

Figure 1. Different coarse-graining strategies for poly-disperse powders (Lu et al. 2018) 


\subsection{Simulation settings}

The travelling fluidized bed apparatus and its auxiliary components, shown in Figure 2(a), were designed to be a robust test platform, easily disassembled, transported and remounted, ensuring identical geometry and operation in different locations. Key features of the equipment include: a cylindrical fluidization vessel consisting of a $0.96 \mathrm{~m}$ long $\times$ $0.133 \mathrm{~m}$ inner diameter dense bed section, surmounted by a $1.36 \mathrm{~m}$ long $\times 0.190 \mathrm{~m}$ inner diameter freeboard section, connected by an inclined transition, angled at $30^{\circ}$ to the vertical. A perforated distributor plate is used to maintain sufficient pressure drop for operation at different superficial gas velocities. More details of the equipment are provided elsewhere (Dubrawski et al., 2013; Tebianian et al., 2015b).

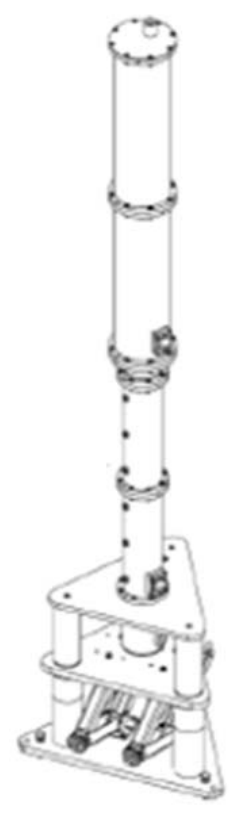

(a)

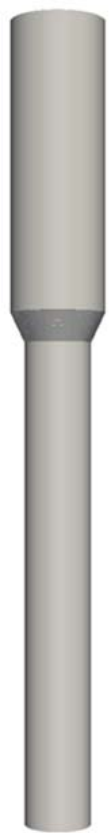

(b)

Figure 2. Travelling fluidized bed (TFB): (a) experimental setup; (b) simulation geometry

The computational domain used in the simulation is shown in Fig. 2(b). The MFIX Cartesian grid cut-cell technique is used to resolve the geometry, in which a Cartesian grid is adopted to discretize the computational domain, while boundary cells are truncated to conform to the internal surface of the fluidization column (Dietiker et al., 2009; Dietiker, 2015). In the simulation, gas flows into the bed from the bottom, with a constant gas inlet velocity boundary condition, and leaves from its top, where a constantpressure boundary condition is imposed. A no-slip wall boundary condition is used for the gas phase. 


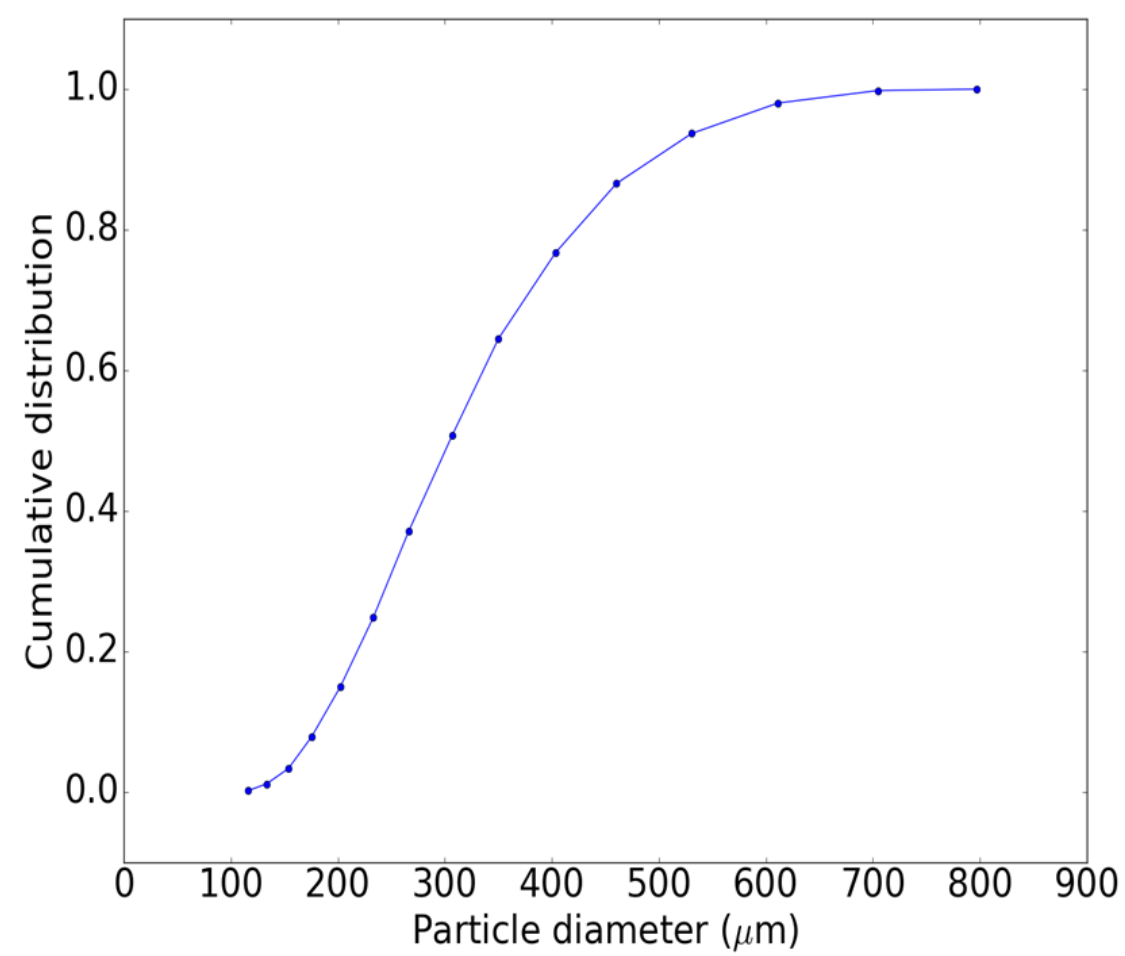

Figure 3. Particle size distribution of sand particles tested in the travelling fluidized bed.

The experimental particulate materials tested were silica sand (Lane Mountain LM50) and spent fluid cracking catalyst. These particles traveled with the equipment as a further measure towards achieving identical operating conditions at each participating location. Only the sand particles, belonging to Geldart group B, were studied in this paper. The experimentally measured particle size distribution (PSD) is shown in Figure 3. The Sauter mean diameter $\left(\mathrm{d}_{32}\right)$ was $0.312 \mathrm{~mm}$ and $0.292 \mathrm{~mm}$ before and after the experiments, and the particle density was $2644 \mathrm{~kg} / \mathrm{m}^{3}$, with a minimum fluidization velocity of $0.0796 \mathrm{~m} / \mathrm{s}$ and a terminal settling velocity in air of $0.73 \mathrm{~m} / \mathrm{s}$. Experiments were conducted using the RPT and PEPT techniques to measure the solid velocity of the bulk bed material inside the system. The properties of the tracer particles are provided in Table 1, together with the average properties of the bulk sand particles.

Table 1: Key properties of bulk sand particles and tracer particles used in the experimental study

\begin{tabular}{|l|c|c|c|}
\hline \multicolumn{1}{|c|}{ Particles: } & Sand & RPT tracer & PEPT tracer \\
\hline Density $\left(\mathrm{kg} / \mathrm{m}^{3}\right)$ & 2644 & 2000 & 3000 \\
\hline Diameter $(\mathrm{mm})$ & $\begin{array}{c}0.312 / 0.292(\text { Sauter } \\
\text { mean })\end{array}$ & $\begin{array}{c}0.400(\text { single } \\
\text { particle })\end{array}$ & $\begin{array}{c}0.300(\text { single } \\
\text { particle })\end{array}$ \\
\hline Shape & Irregular & Nearly spherical & Irregular \\
\hline
\end{tabular}

As can be seen from Table 1, the tracer particle key physical properties, (density, size and shape), differed from those of the bulk sand particles. To take advantage of the two approaches shown in Figure 1 for modeling PSD in coarse-grain DEM simulations, different tracer particles are simulated with the first approach, i.e., a constant coarse-grain 
size ratio, but different numerical particle diameters for greater accuracy. On the other hand, the full PSD of bulk material is simulated through the second approach, with variable coarse-grain size ratio and a constant numerical particle diameter to take advantage of the computational efficiency.

Only a single tracer particle was used in both the RPT and PEPT experimental measurements. In order to characterize the flow, the experiments must run for long periods of time to collect sufficient data points for analysis. The durations of experiments for our RPT and PEPT measurements were 8 and 3.5 hours, respectively. Numerical simulations covering such long durations are not feasible, due to the resulting high computational cost. On the other hand, it is appropriate in the numerical modeling to reduce the simulation time greatly by introducing and following many tracer particles, so long as these tracer particles constitute only a small fraction of the particles in the bed.

In total, about 3 million numerical particles with their key physical properties corresponding to silica sand were tracked, and the particle size distribution was realized by varying the coarse-grain size ratio, $n$. In general, a coarse grain size ratio of 5 was used for the majority of coarse-grained particles to represent about 0.4 billion sand particles. Considering the slight change in particle size distributions before and after the experimental test, the PSD shown in Figure 2 with a mean diameter of $302 \mu \mathrm{m}$ was used in the simulation. Different tracer particles with specific diameters and densities were tracked: 1000 numerical particles for each of RPT, PEPT and sand tracer particles. The detailed simulation parameters are listed in Table 2.

Table 2: Parameters used in the numerical simulations

\begin{tabular}{|l|l|}
\hline Parameter or property & Value \\
\hline Gas density, $\rho_{\mathrm{g}}\left(\mathrm{kg} / \mathrm{m}^{3}\right)$ & 1.205 \\
\hline Gas viscosity, $\mu_{\mathrm{g}}(\mathrm{Pa} . \mathrm{s})$ & $1.8 \times 10^{-5}$ \\
\hline Coarse-grained sand particle diameter, $d_{\mathrm{p}}(\mathrm{mm})$ & 1.51 \\
\hline Coarse-grained sand particle number, $n_{\mathrm{p}}$ & $3,034,944$ \\
\hline Sand particle density, $\rho_{\mathrm{p}}\left(\mathrm{kg} / \mathrm{m}^{3}\right)$ & 2,644 \\
\hline Static bed height, $H_{\mathrm{S}}(\mathrm{m})$ & 0.82 \\
\hline Coarse-grained RPT tracer diameter, $d_{\mathrm{RPT}}(\mathrm{mm})$ & 2.0 \\
\hline RPT tracer number, $N_{\mathrm{RPT}}$ & 1000 \\
\hline RPT tracer density, $\rho_{\mathrm{RPT}}\left(\mathrm{kg} / \mathrm{m}^{3}\right)$ & 2000 \\
\hline Coarse-grained PEPT tracer diameter, $d_{\mathrm{PEPT}}(\mathrm{mm})$ & 1.50 \\
\hline PEPT tracer number, $N_{\mathrm{PEPT}}$ & 1000 \\
\hline PEPT tracer density, $\rho_{\mathrm{PEPT}}\left(\mathrm{kg} / \mathrm{m}^{3}\right)$ & 3000 \\
\hline Superficial velocity, $(\mathrm{m} / \mathrm{s})$ & $0.4,0.6$ \\
\hline Domain size, $(\mathrm{mm})$ & $200 \times 200 \times 1600$ \\
\hline
\end{tabular}




\begin{tabular}{|l|l|}
\hline CFD grid size, $(\mathrm{mm})$ & 5.0 \\
\hline CFD time step, $(\mathrm{s})$ & $5.0 \times 10^{-5}$ \\
\hline
\end{tabular}

The simulations were run in hybrid parallel mode by coupling distributed memory parallel (DMP) and shared memory parallel (SMP), using message-passing interface (MPI) and open multi-processing (OpenMP) on NETL's supercomputer (Gopalakrishnan and Tafti, 2013; Liu et al., 2014). Simulations of $150 \mathrm{~s}$ were conducted. In postprocessing, the first $10 \mathrm{~s}$ were discarded to exclude start-up effects as the flow reached a fully developed state in a few seconds. During the simulations, tracer location and velocity were saved at $100 \mathrm{~Hz}$, and flow field variables including gas and solid velocities and solid volume fraction in the Eulerian grid were saved at $20 \mathrm{~Hz}$ for verification.

\section{Modeling Results}

\subsection{General flow behavior}

In this study, two different superficial velocities, 0.4 and $0.6 \mathrm{~m} / \mathrm{s}$, were simulated. Transient results of the bubble behavior, gas volume fraction, gas phase vertical velocity, solid phase vertical component of velocity and distribution of particle size in the axial direction are shown in Figure 4. Here, the vertical velocities of both phases are average vertical components for each cell. In Figure 4(e), the mean particle size is calculated in each CFD grid by averaging all particles in the cell. The results in Figure 4(e) suggest that, overall, the different size particles are well mixed inside the system, except for the bottom region, immediately above the distributor. Due to less vigorous mixing, and hence size segregation in that region, coarse particles tend to accumulate there. It should be noted that a uniform velocity is used in the simulation as a boundary condition, without resolving the detailed perforated plate distributor employed in the experiments. The uniform velocity boundary is usually a reasonable assumption for a distributor plate, as long as the pressure drop through it is sufficiently high (Karri and Werther, 2003). However, it fails to capture micro-jetting flow immediately above the distributor. Hence, the weak particle segregation near the distributor predicted by the numerical simulation might not match the experimental behavior accurately. 


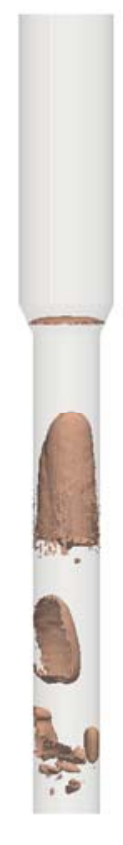

(a)

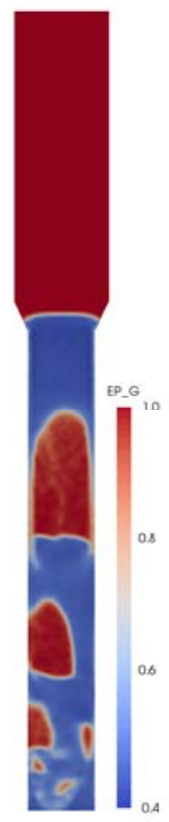

(b)

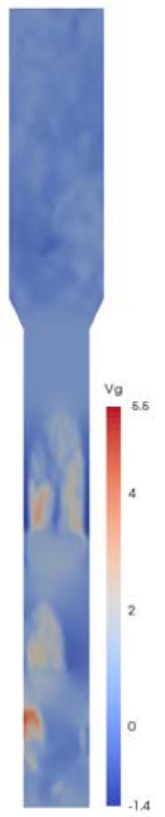

(c)

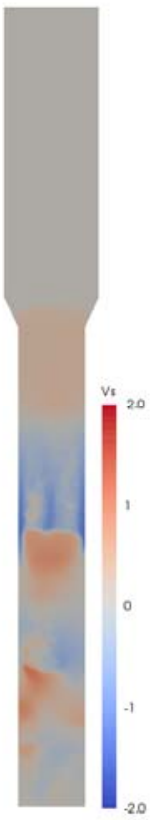

(d)

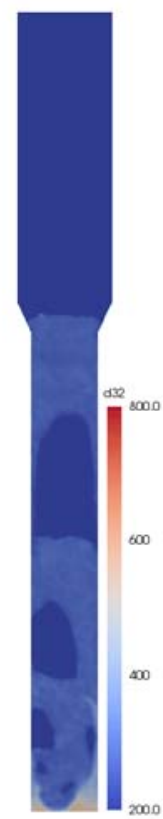

(e)

Figure 4. Transient simulation results (a) bubble contour defined with voidage of 0.8 ; (b) voidage; (c) gas velocity $(\mathrm{m} / \mathrm{s})$; (d) solid vertical component of velocity $(\mathrm{m} / \mathrm{s})$; and (e) mean particle diameter $(\mu \mathrm{m})\left(\mathrm{V}_{\mathrm{s}}\right.$ : solid-phase vertical component of velocity calculated by averaging particle velocities in each fluid cell, d32: Sauter mean diameter of particles in each fluid cell, $\mathrm{U}_{\mathrm{g}}=0.40 \mathrm{~m} / \mathrm{s}$ ).

Simple time-average results are shown in Figure 5 based on averaging over a time interval of $140 \mathrm{~s}$. Figure 5(a) shows the mean voidage distribution in a vertical central slice. The distribution of voidage is realistic compared to the overall bed average of 0.6 0.7, determined by the different experimental measurements. Detailed comparison with the experimental data will be reported in a future study focusing on systematic validation. Figures 5(b) and (c) show the mean velocity fields for both gas and solid phases. It is evident that the mean velocity field is not very symmetric, even for $140 \mathrm{~s}$ of simulation. This may be due to the specific fluidization flow regime, involving slowly rising slugs. As seen in Figure 5(d), where the overall mean particle size is shown, the coarse particles accumulate near the bottom, indicating that size segregation of sand particles only takes place near the distributor because of less vigorous mixing there. For most of the system, the cell-average particle diameter is close to the Sauter mean as the consequence of good solid mixing. The small mean particle size in the freeboard is mainly due to the fact that a zero particle size is assumed when there are no particles present in a cell. The results here justify the success of many previous CFD studies modeling fluidized beds which have assumed mono-disperse particles. 


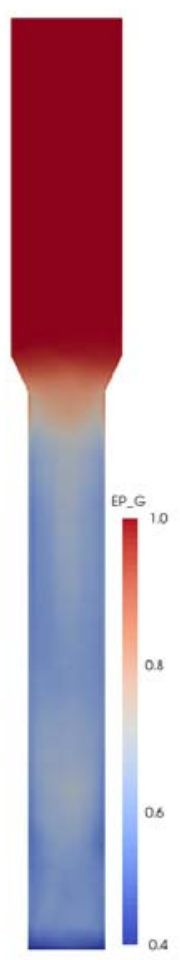

(a)

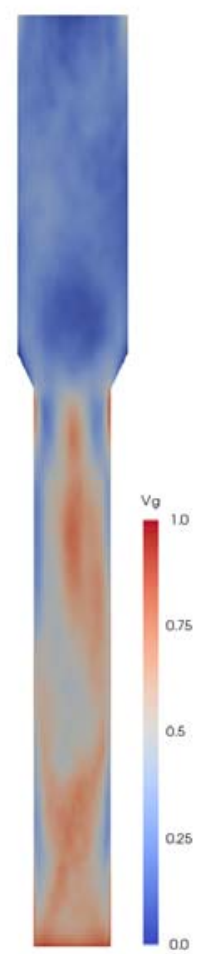

(b)

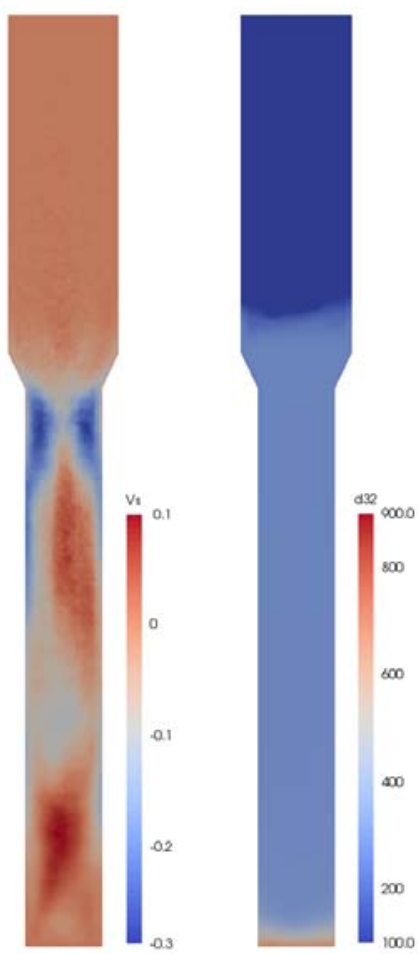

(d)

Figure 5. Sliced view of time-average results for a superficial gas velocity of $0.4 \mathrm{~m} / \mathrm{s}$ : (a) time-average gas volume fraction; (b) time-average vertical component of gas velocity $(\mathrm{m} / \mathrm{s})$; (c) time-average vertical component of particle velocity $(\mathrm{m} / \mathrm{s})$; and $(\mathrm{d})$ timeaverage distribution of mean particle diameter. $\left(\mathrm{U}_{\mathrm{g}}=0.40 \mathrm{~m} / \mathrm{s}\right.$.)

\subsection{Face-average and volume-average particle velocities}

In the RPT and PEPT experiments, the trajectory of a single tracer particle was tracked for 8 and 3.5 hours, respectively. Two different averages were used when analyzing the tracer data, namely a face-average (crossing-based) and a volume-average (volumebased). In the former case, the vertical component of all velocity vectors of particles crossing the measurement level at each time are counted and these values are then averaged. In the second case, the vertical velocity component of particles located inside a specified volume are counted within the examined time period, and then averaged. These average values are taken to characterize the bulk flow behavior. In the current simulations, both approaches have been utilized to analyze and compare the numerical results. Since it is possible to follow the trajectories of all particles in the simulated bed, one thousand such virtual trajectories were computed for each of the following three cases: tracers with the same properties as the experimental PEPT tracer; tracers with the same properties as the RPT tracer; and tracers representing the bulk sand, each within the same $150 \mathrm{~s}$ simulation time.

A typical tracer particle trajectory is shown in Figure 6 as an example to illustrate the face-average and volume-average processing of the data. The face-average of the vertical 
velocity of the tracer particles is realized by counting the particles crossing the specified plane at three levels $(0.24,0.40$ and $0.56 \mathrm{~m})$ above the distributor plate. As explained by Tebianian et al. (2015a), the face-average method is more direct, evaluating the velocity only when the tracer crosses a specific measurement level.

The alternative volume-based analysis, commonly used to determine the solid motion in fluidized beds from particle tracking techniques, divides the whole column into a mesh consisting of small cells of finite volume and calculates the local time-average velocity considering the tracer velocity every time that it is inside a cell of interest during the data sampling period.

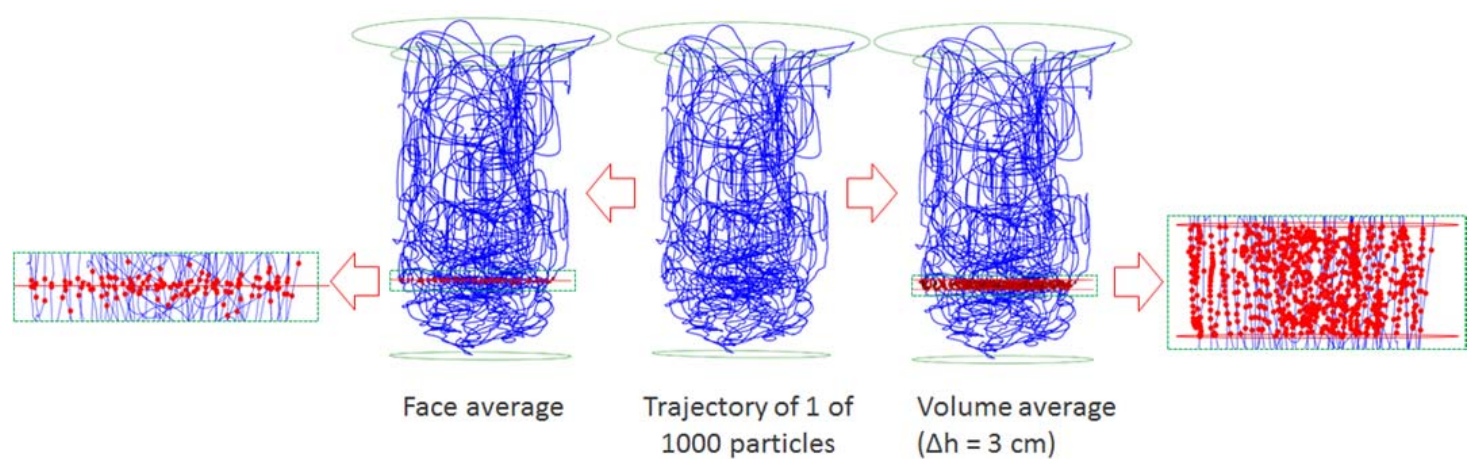

Figure 6. Face-average and volume-average of vertical component of velocity of 1 of 1000 simulated tracer particles for a superficial gas velocity of $0.4 \mathrm{~m} / \mathrm{s}$.

Figure 7 shows radial profiles of the vertical component of time-average particle velocity obtained for all three types of tracer particles based on both analysis approaches. In this case, volume-averaging was performed by counting all tracer particles in a control volume of height $\Delta \mathrm{h}=30 \mathrm{~mm}$, centered $0.24 \mathrm{~m}$ above the distributor plate. These two approaches are the same as adopted in the experiments, and axial-symmetry is assumed, as in the experimental work. The data are averaged with a bin width of $\Delta \mathrm{d}=10 \mathrm{~mm}$ in the radial direction. Note that all tracer particles are taken into account for analysis purposes. In the experiments, the RPT and PEPT tracers provided different results; whereas, simulation predictions for different tracer particles were very similar in the simulations. These results indicate that the discrepancy between RPT and PEPT measurements is unlikely to be caused by the use of different tracer particles.

On the other hand, there are significant differences between the results obtained by the two different data averaging approaches, as can be seen through the average values shown in Figure 7. Compared to the face-averaged particle velocity, the magnitude of the volume-averaged particle velocity is lower in the central region, and greater near the wall, hence showing less variation in the radial direction. A detailed comparison of the simulation predictions and the experimental results is presented in the following section. The average velocities of the three different types of tracer particles are shown by a single dashed line in Figure 7, as differences due to unmatched tracer properties are nearly indistinguishable. 


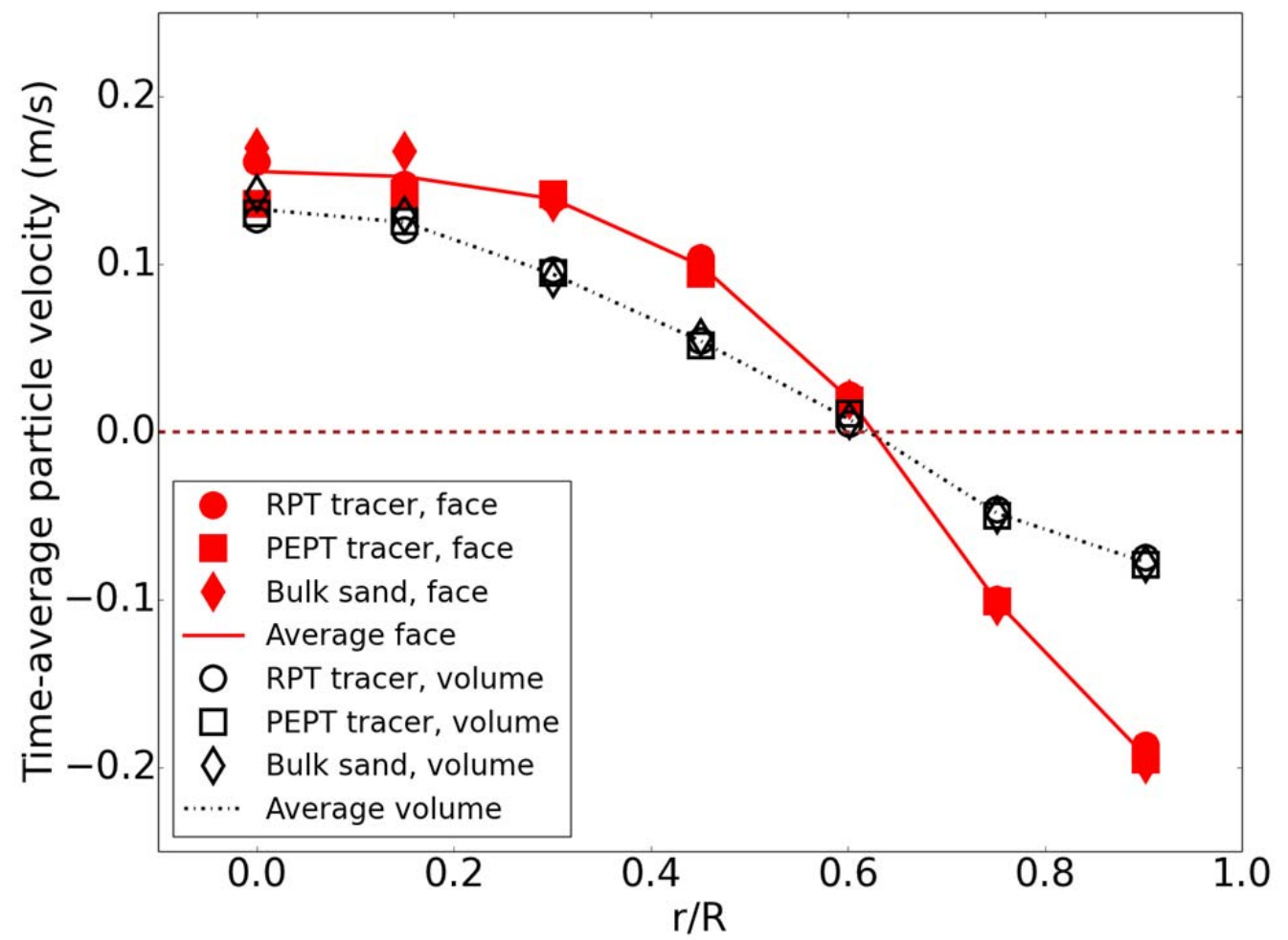

Figure 7. Comparison of face-average (red, filled symbols) and volume-average (black, open symbols) particle velocity predicted by the CFD-DEM simulation model with different tracer particles at $\mathrm{h}=0.24 \mathrm{~m}$ for a superficial gas velocity of $0.4 \mathrm{~m} / \mathrm{s}$. The lines show averages of three different tracers. (Data are averaged at each radial position, with axisymmetric assumption.)

\subsection{Verification of tracer technique}

The goal of both the experiments and the CFD-DEM simulations was to study the bulk flow behavior through representative tracer particles. It is important to verify that the tracer movements reflect the bulk flow of interest. To determine whether the velocities obtained from the tracer particles are representative of the bulk solid flow, the solid velocity field calculated by averaging the velocities of all particles in each computational cell, referred to as the Eulerian velocity for the solid phase, is compared with the tracer data. In each computational cell, the Eulerian solid velocity, $\mathbf{u}_{s}$, is calculated as $\mathbf{u}_{s}=\sum \mathbf{v}_{p}^{i} K\left(\mathbf{x}_{i}, \mathbf{x}_{c}\right)$

where $\mathbf{v}_{p}^{i}$ is the vertical component of the velocity of particle $i$, and $K$ is the interpolation weight of particle $i$ in computational cell $c$. The Eulerian solid velocity, together with the solid volume fraction, is stored in the numerical grid for analysis of the bulk flow behavior. 
Proper time-averaging of the bulk flow field is needed to compare with the information extracted from the experimental tracer data over long periods of time. Three types of time-averaging are considered. First simple time-averaging is applied when the flow reaches a fully-developed state:

$\bar{V}_{s}=\left\langle V_{s}\right\rangle$

The $<>$ brackets indicate simple arithmetic averaging. Here we only focus on the vertical component of $V_{s}$. It should be noted that this simple time-average requires the velocity field at each time; hence it is not applicable to the tracer data, which only provide limited coverage of the velocity field at each time. Considering the fact that the likelihood of a tracer particle being detected in a small volume is proportional to the local solid concentration, the Favre average is also used to calculate the mean solid velocity for comparison (Verma et al. 2013; Li et al. 2015). In the simulation, the average vertical component of particle velocities in a control volume can be calculated by the Favre average,

$\tilde{V}_{s}=\frac{\left\langle\varepsilon_{s} V_{s}\right\rangle}{\left\langle\varepsilon_{s}\right\rangle}$

where $V_{\mathrm{s}}$ and $\varepsilon_{\mathrm{s}}$ are the vertical component of particle velocity and the solid volume fraction, respectively. The simple time average and Favre average would yield the same results if the flow were homogenous. However, in most cases they differ due to the inherently heterogeneous structures in gas-solid flows, resulting in the local particle concentration and particle velocity being correlated (Bi et al., 1996).

To be comparable with the face-average solid velocity from tracer data, the solid flux weighted velocity, referred to as face-average bulk flow, is calculated as

$\tilde{V}_{f}=\frac{\left\langle\left|\varepsilon_{s} V_{s}\right| V_{s}\right\rangle}{\left\langle\left|\varepsilon_{s} V_{s}\right|\right\rangle}$

It should be noted that all calculations are based on the Eulerian solid velocity and solid volume fraction, and hence correspond directly to the popular Two-fluid model (TFM) simulations, where no individual particle velocities are available.

Figure 8 presents profiles of the vertical component of solid velocity obtained by different averaging techniques from the bulk flow, as well as velocity profiles from the analysis of numerical tracer particle data. For the bulk flow, the velocity profiles from simple time-average and Favre-average are quite different, with the former showing less radial variation. The discrepancy is most significant in the central region and moderate near the wall. This is consistent with the results from a similar analysis from a two-fluid model simulation by $\mathrm{Li}$ (2015). The velocity profile derived from the tracer data with volume-averaging agrees well with the bulk velocity profile from the Favre-average, indicating that the tracer particles used in the simulation are able to follow the bulk flow behavior of the system. On the other hand, the flux-weighted mean solid velocity, i.e. face-average bulk flow, agrees well with the face-average tracer data, indicating that the analyses are consistent. In addition to the mean particle velocity, the solid velocity distributions for different types of particles are compared in Figure 9, further confirming the consistency between tracer data and bulk flow. 


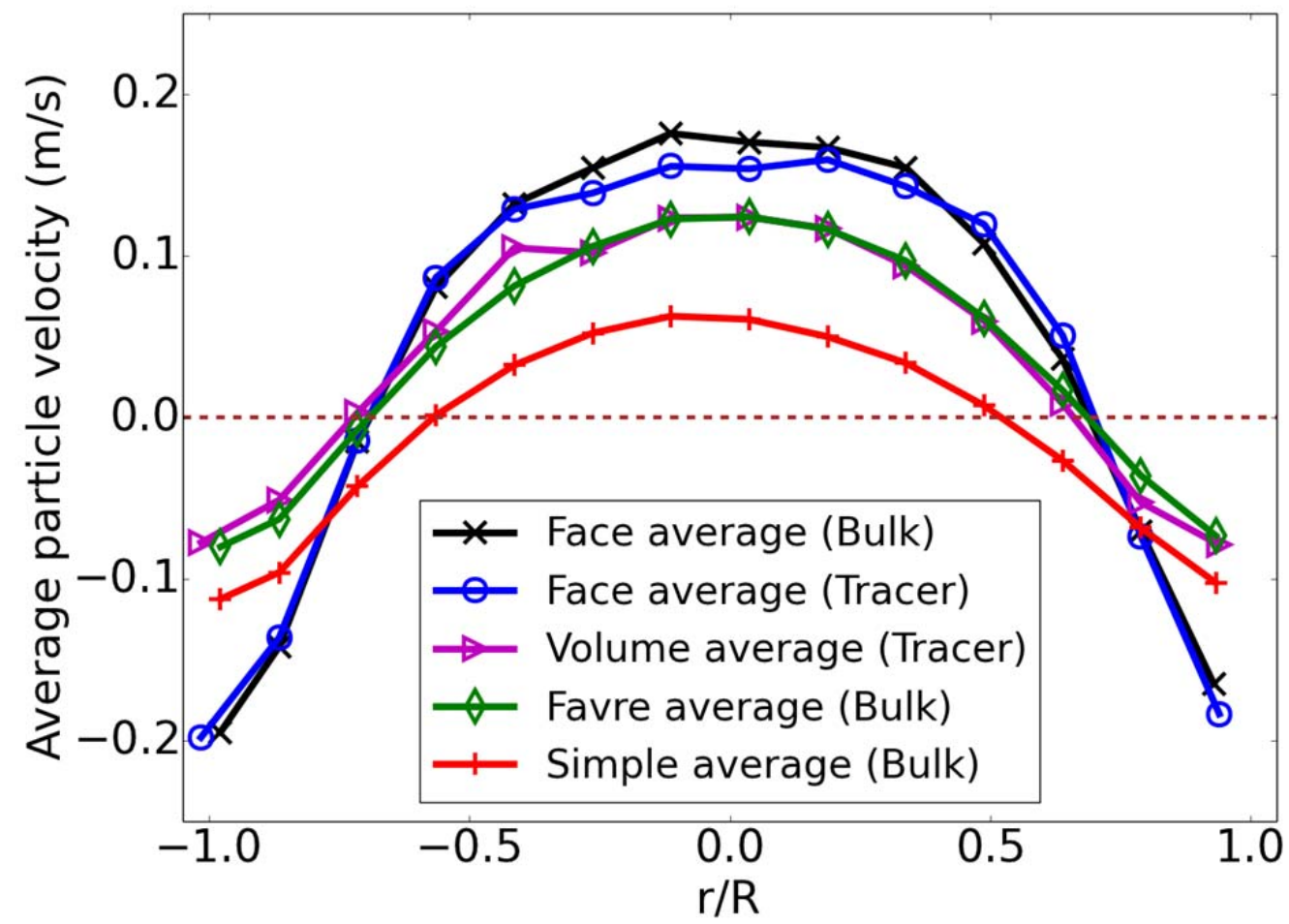

Figure 8. Comparison of simulated radial profiles of vertical component of predicted particle velocity obtained by different averaging methods at $\mathrm{h}=0.24 \mathrm{~m}$, with a control volume of $30 \mathrm{~mm}$ width for the volume average, and with the face average at center of control volume (Superficial gas velocity $=0.4 \mathrm{~m} / \mathrm{s}$ ).

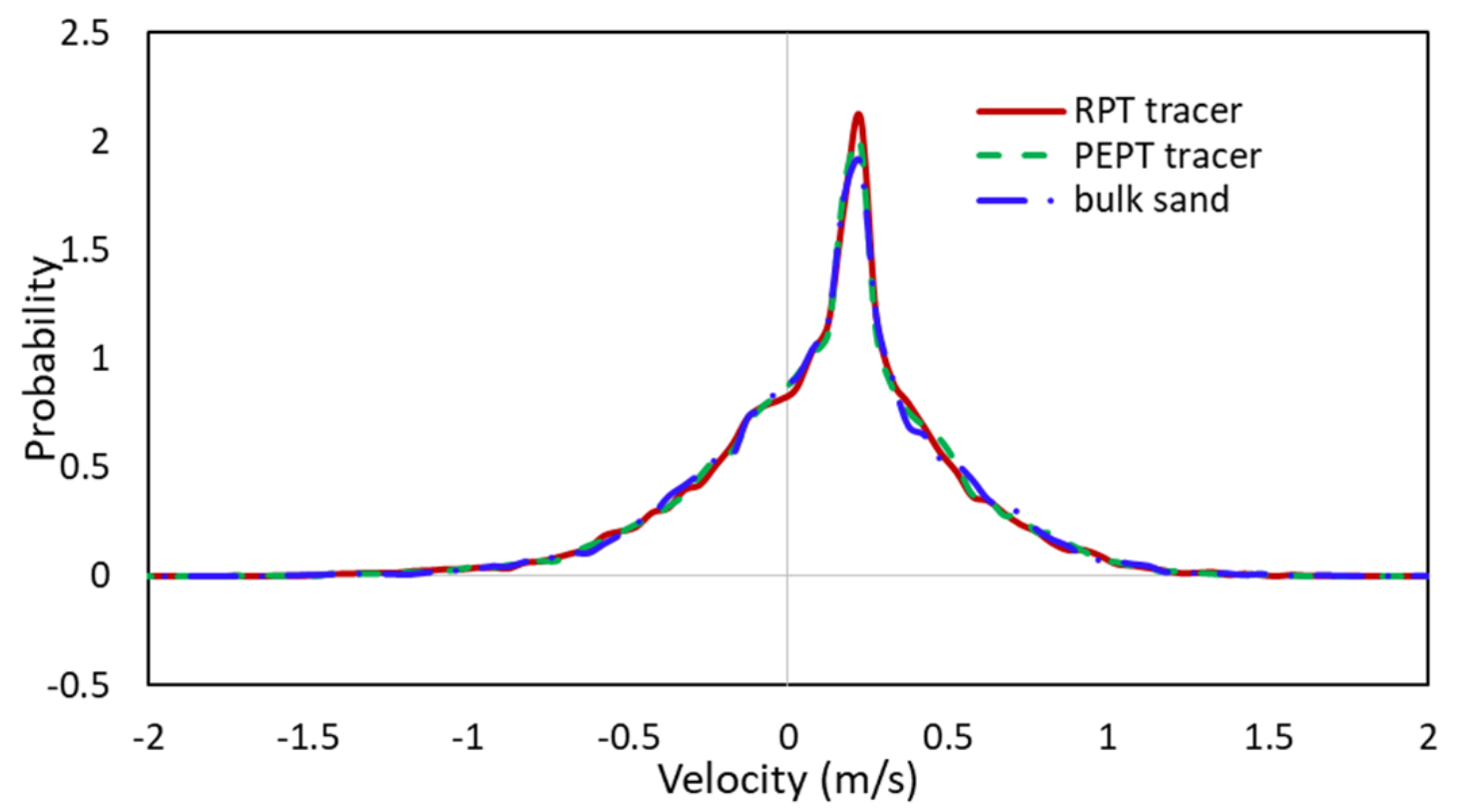


Figure 9. Comparison of velocity distributions for different particles extracted from a $4 \times 4 \times 4 \mathrm{~cm}$ control volume for the simulation with a superficial gas velocity of $0.4 \mathrm{~m} / \mathrm{s}$

The results in Figure 8 highlight that the experimental data and numerical results must be compared on a consistent basis for validation purposes. Both volume-average and faceaverage analyses of tracer data produce meaningful information on the bulk flow field. However, the simple time-average of the Eulerian velocity for the solid phase apparently cannot be used for comparison with the experimental data from RPT and PEPT measurements as no corresponding measurement can be made through these techniques. Considering the simplicity in data processing and straight-forward physical meaning, we focus in the following analyses on the Favre-average and volume-average tracer data.

For the results presented in Figure 8, the radial profile is obtained by analyzing data in cubic control volumes of dimensions of $\mathrm{H} \times \mathrm{W} \times \Delta \mathrm{d}$, as illustrated in Figure 10. It is of interest to see the effect of control volume, as well as the number of tracer particles, on the solid velocity profiles. With that, different sizes for the control volume, as summarized in Table 3, are utilized for tracer data analyses.

Table 3: Control volume dimensions for tracer data analysis as shown in Figure 10 (unit: $\mathrm{mm})$

\begin{tabular}{lccc}
\hline & W & H & $\Delta \mathbf{\Delta d}$ \\
\hline Coarse & 30 & 30 & 10 \\
Medium & 20 & 20 & 10 \\
Fine & 10 & 10 & 10 \\
\hline
\end{tabular}




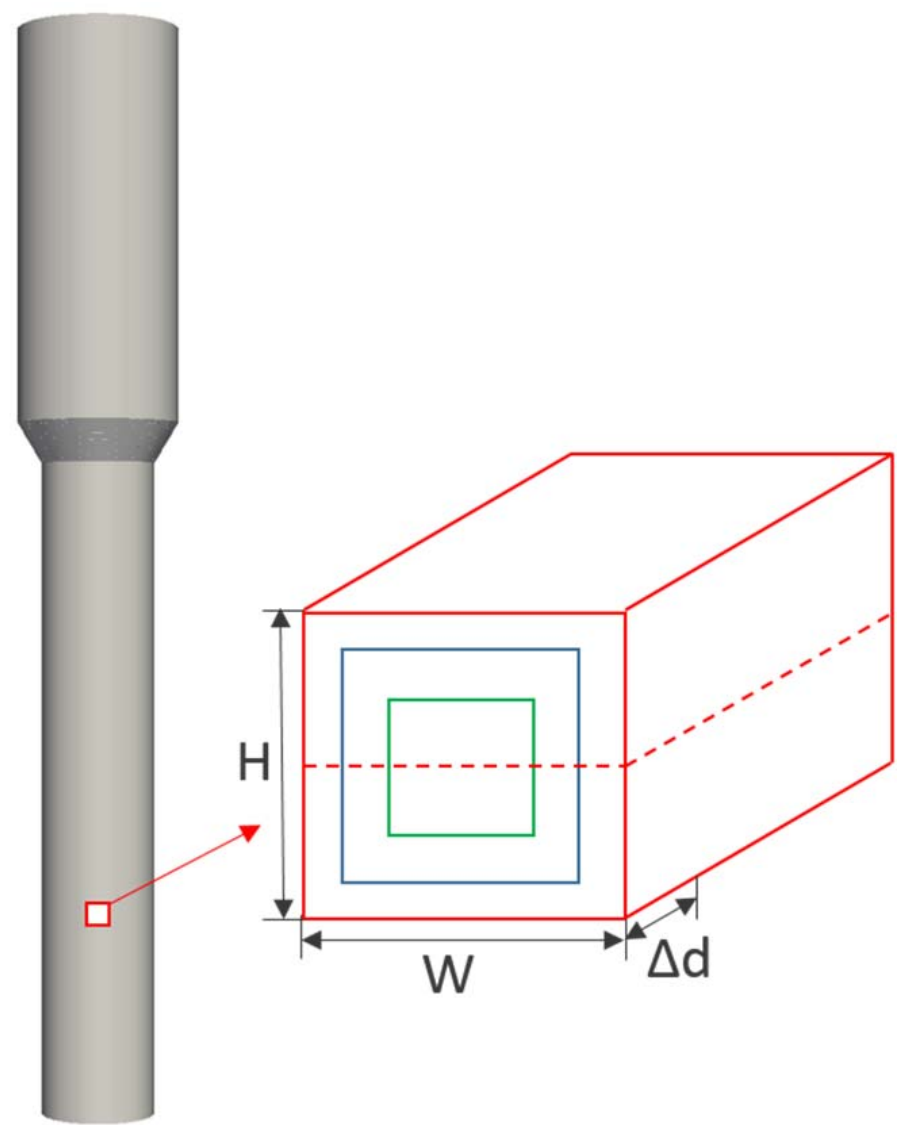

Figure 10. Control volume for comparing tracer particle and bulk particle flows

Figure 11 compares the velocity profiles from the tracer data using different control volumes and tracer counts. In addition, data from different numbers of tracer particles are also tested to assess their impact on the velocity profiles. The bulk velocity profile is shown for reference. As expected, increasing the size of the control volume and the number of tracer particles smoothens the velocity profile, while strong variations tend to persist when fewer tracer particles and smaller control volumes are used for analysis. Since the number of tracer particles observed in a given volume is directly related to the physical time of the experimental tracer tracking, these results highlight the need for long-duration experiments for data analysis. 

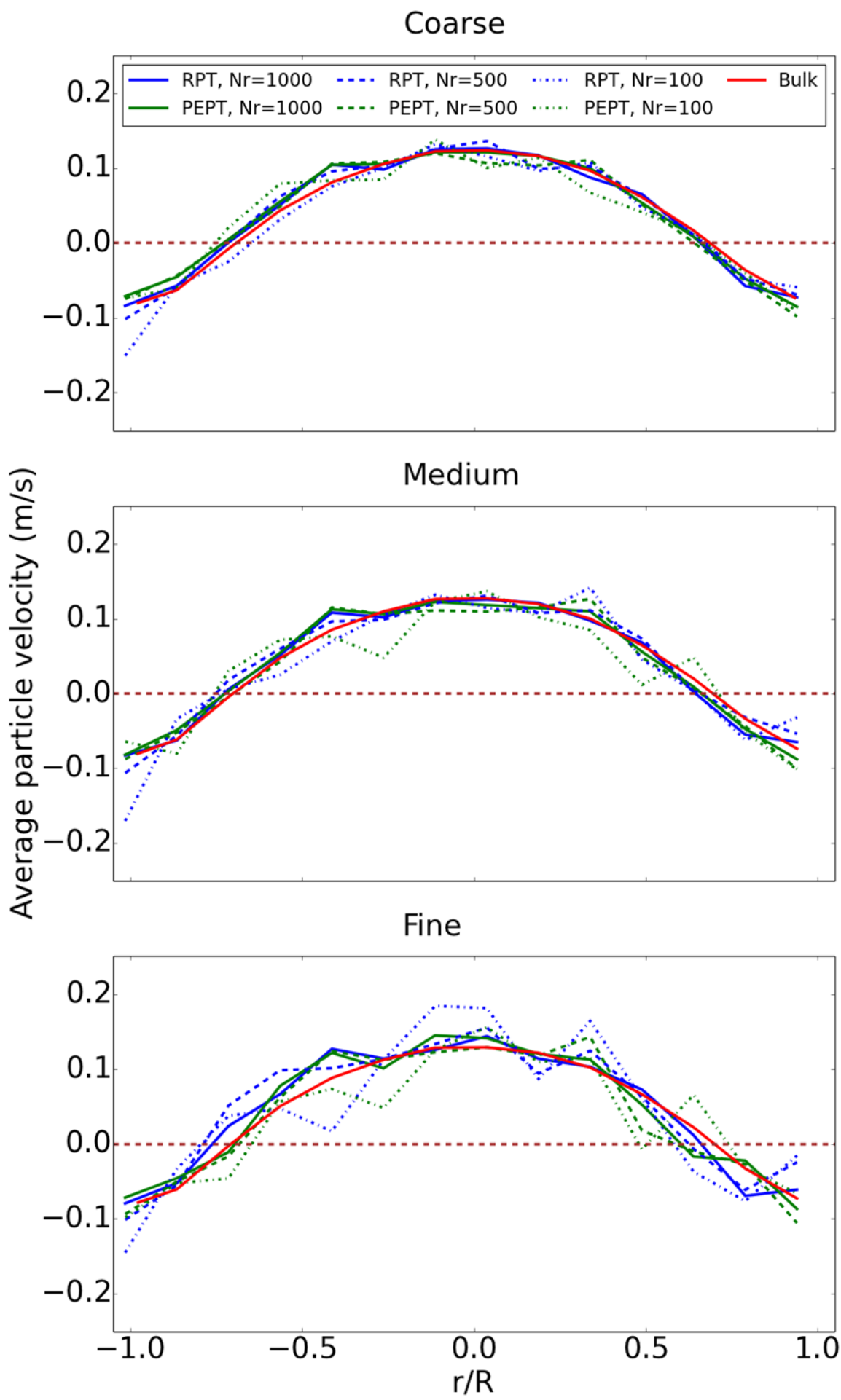

Figure 11. Comparison of radial profiles of average velocities with different control volumes at $\mathrm{h}=0.24 \mathrm{~m}$ for a superficial gas velocity of $0.4 \mathrm{~m} / \mathrm{s}$. 


\subsection{Comparison of simulation and experimental results}

In the experiments, four different approaches, namely optical probe, borescope, RPT and PEPT, from leading research groups in three countries were utilized to measure vertical components of particle velocity in the travelling fluidized bed. Different approaches led to different results, even under identical operating conditions, as shown in Figures 12 and 13. The reason for the significant discrepancy is unclear, as the current study tends to rule out the hypothesis that for the RPT and PEPT results the spread in data was due to differences in tracer properties. Detailed comparison between the simulation and experimental results under two different sets of operating conditions are shown. To be consistent with the experimental measurements, numerical data are averaged at each radial position to obtain a single radial profile. For the RPT and PEPT measurements, the volume-average data are compared with the Favre average numerical results. The optical probe and borescope measurements are shown for reference purposes only. Overall, the simulation results fall in the range of the experimental data and show trends similar to those from the experimental measurements.

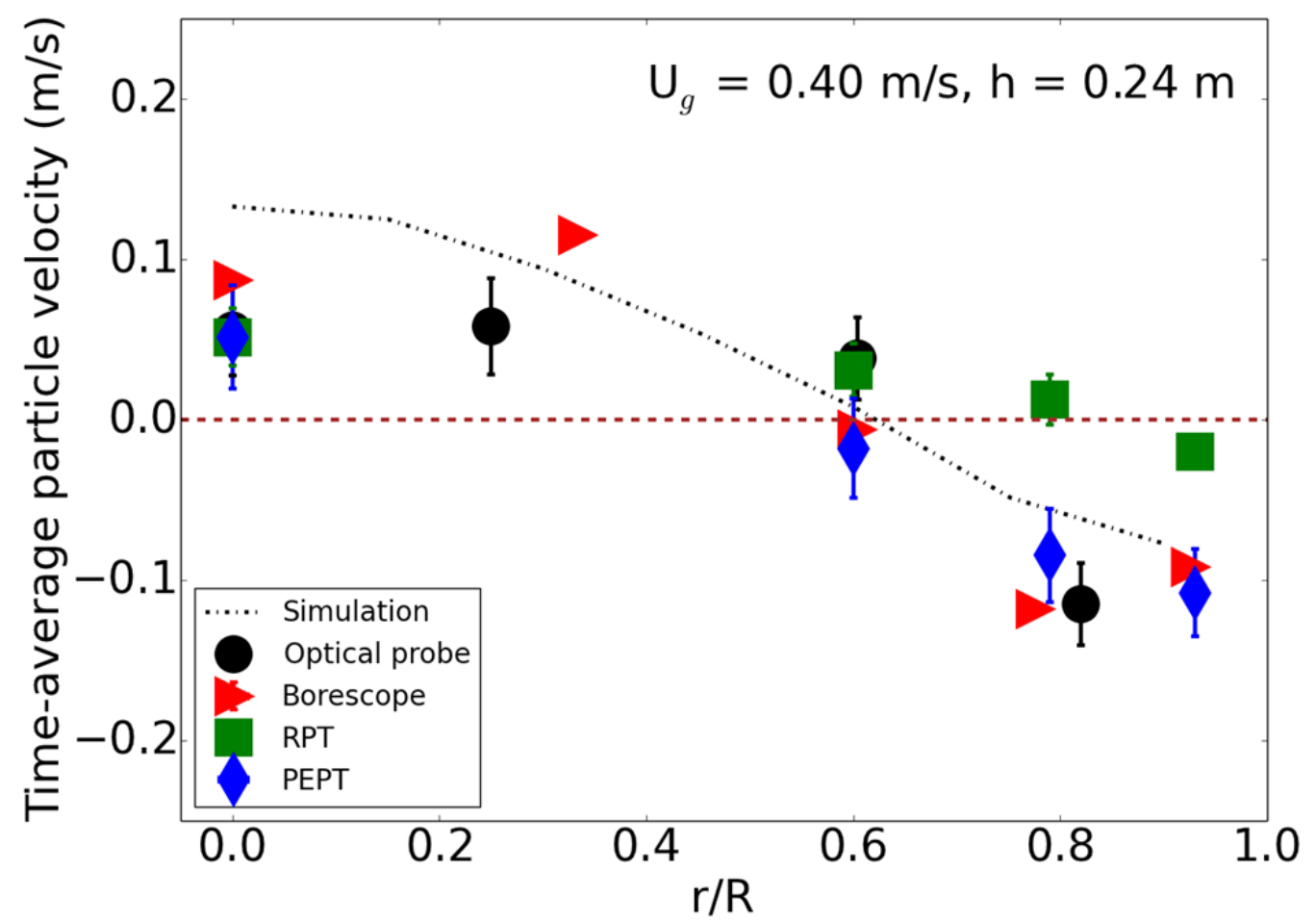

Figure 12 . Radial profiles of time-average solid velocity at $\mathrm{h}=0.24 \mathrm{~m}$ by volumeaveraging, $\mathrm{U}_{\mathrm{g}}=0.40 \mathrm{~m} / \mathrm{s}$. (Data are averaged at each radial position with axial symmetry assumed.) 


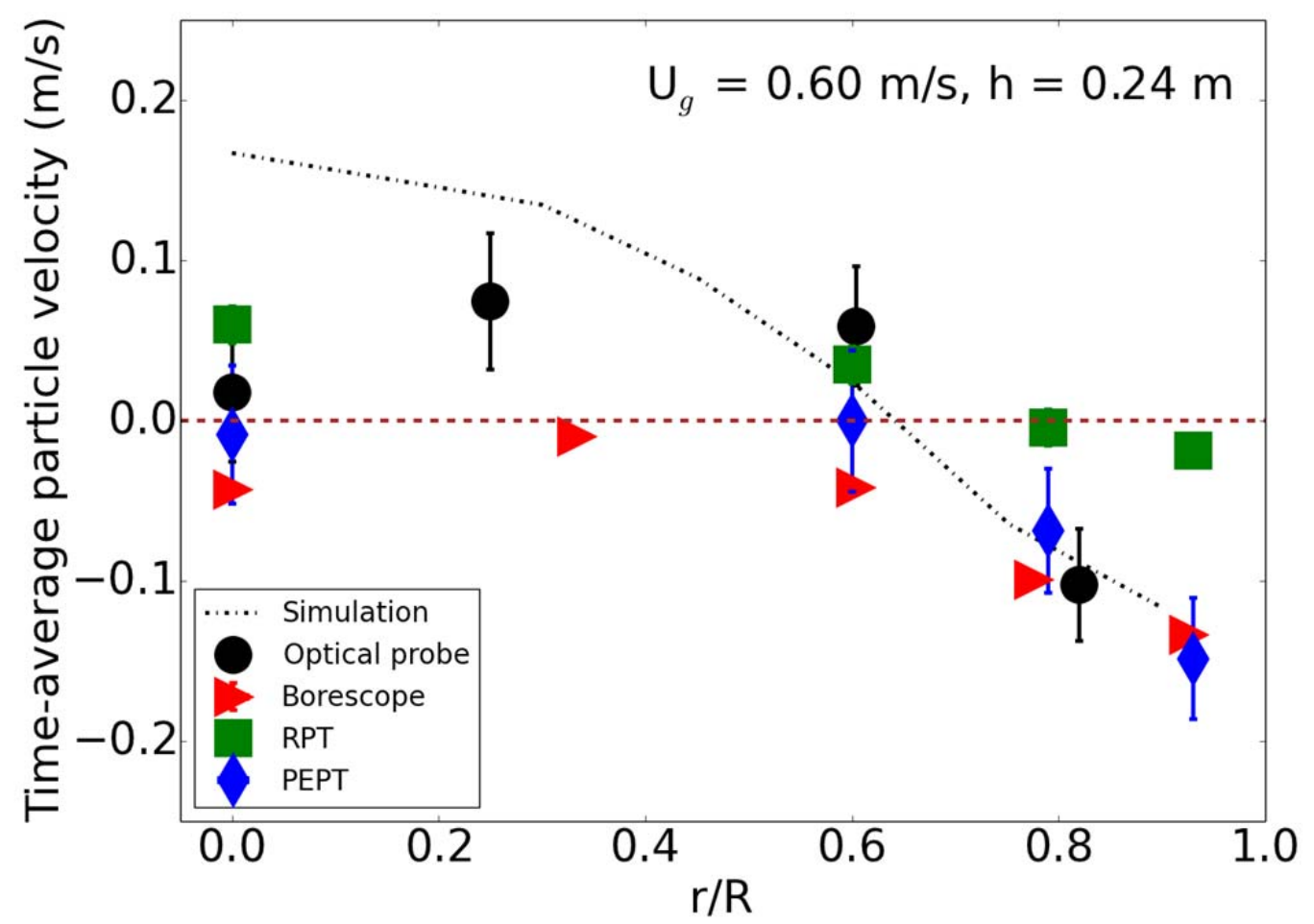

Figure 13. Radial profiles of time-average vertical component of particle velocity at $\mathrm{h}=0.24 \mathrm{~m}$ by volume-averaging, $\mathrm{U}_{\mathrm{g}}=0.60 \mathrm{~m} / \mathrm{s}$. (Data are averaged at each radial position with axial symmetry assumed.)

\section{Further Discussion}

The current study suggests that differences in the particle size and density of the tracer particles used in the RPT and PEPT experiments, as well as differences in these properties from the bulk bed material of the travelling fluidized bed, should yield no significant discrepancy between the RPT and PEPT measurements. However, certain limitations do exist. First, the current modeling approach assumes that all bulk and tracer particles are spherical. It is not able to capture the influence of particle shape and surface properties among the different tracer particles and the bulk sand particles. Secondly, although coarse-grained particle methods have been evaluated in the literature for multiple problems on various length and time scales, the applicability of this method to study the behavior of individual tracer particles in fluidized beds is unproven. To clarify that, a standard DEM simulation without coarse-graining was conducted for a small-scale system, i.e. with each numerical particle representing one real particle. Due to the large number of particles contained in the traveling fluidized bed, a small-scale pseudo-2D system, shown in Figure 14(a), was set up to determine whether the RPT tracer and PEPT tracer particles would behave differently from the bulk particles. A thickness of only 10 $\mathrm{mm}$ was used to reduce the number of particles, and a periodic boundary condition was imposed in the thickness direction for the front and back domain surfaces. With the periodic boundary condition, particles confined by the front and back surfaces were 
allowed to cross the domain, better mimicking the three-dimensional flow behavior in the cylindrical column.

The small-scale system contained about 3 million particles and was simulated for a similar superficial gas velocity of $0.40 \mathrm{~m} / \mathrm{s}$ to match the operating conditions of the travelling fluidized bed. The same particle properties as in the travelling fluidized bed system were used in the simulation, with different types of tracer particles simulated. For all numerical particles, the measured physical properties were used. Similar analysis was conducted for the numerical data collected for different tracer particles, as well as the bulk flow. Figure 14(b) shows the average particle velocities obtained from different types of tracer particles. It can be seen that the results for different types of tracers, i.e., bulk sand, RPT tracer and PEPT tracer particles, are very close to each other. The almost indistinguishable results for the RPT and PEPT tracer particles confirm the conclusion from the coarse-grain DEM simulation. Additional simulations were conducted by increasing the particle friction coefficient to account for the effects of particle shape and surface properties without explicitly resolving them. Note that the detailed effects of irregular particle shape cannot be accurately captured due to the spherical particle assumption in the current DEM. Similar results were obtained, not shown here, with almost identical particle velocities extracted from different types of tracer particles. This further confirms that both the RPT and PEPT tracer particles would yield virtually the same velocity measurements for the traveling fluidized bed.

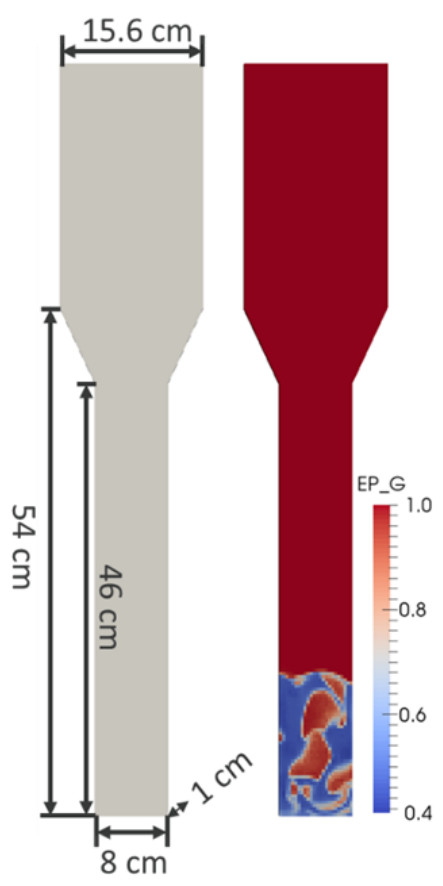

(a)

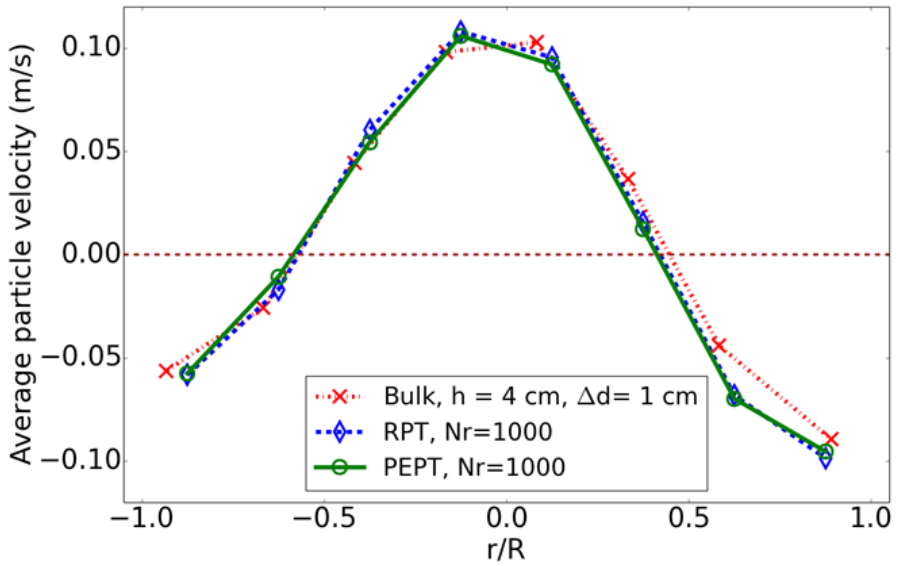

(b)

Figure 14. Pseudo-2D DEM simulation for verification purposes: (a) simulation set-up and snapshot; (b) lateral profiles of vertical component of particle velocity from different tracer particles. 
Having shown that the diameter and density of the tracer particles deployed in the RPT and PEPT experiments were very unlikely to be responsible for the differences in experimentally measured vertical components of particle velocity, further studies are still needed to understand the significant discrepancy between the RPT and PEPT data. We feel that factors playing a role might be some combination of the following:

a) different non-spherical shapes of tracer particles;

b) differences in surface energies or electrostatic properties of tracer particles;

c) factors such as relative humidity that were not controlled to be identical and which could have played a significant role with respect to electrostatic and van der Waals inter-particle forces;

d) subtle differences in the experimental techniques, such as different sampling rates and life-times of the RPT and PEPT tracer particles;

\section{Conclusions}

The current study focused on matching tracer particle properties with bulk particle properties to characterize the solid flow in a fluidized bed through numerical simulations and comparison with experimental results obtained from the travelling fluidized bed. A coarse-grained CFD-DEM was utilized to simulate the poly-disperse system inside a fluidized bed, with particles lumped into parcels to reduce the simulation time, whilst the bulk particle size distributions were maintained. Different types of tracer particles, corresponding to previous RPT and PEPT experimental measurements, were simulated to help understand the significant discrepancy between these two types of tracer observed experimentally. Consistent with the experimental analyses, both face-average and volume-average methods were employed in post-processing the numerical tracer data. Simulations based on the properties of the two different tracer particles used in the RPT and PEPT experiments yielded almost identical results, implying that the discrepancies between the RPT and PEPT measurements were probably not caused by differences in the physical properties of the tracer particles utilized in the experiments.

The numerical tracer data were further compared with the bulk flow predicted by the simulation code. It was found that Favre-averages of the vertical components of bulk solid velocities agree well with the volume-averaging of tracer data, and a flux-weighted average of bulk flow matched the face-average tracer data well. The study also confirms that trajectory-following experimental techniques need to be compared on either a faceaveraged or a volume-averaged basis and that this needs to be clearly stated, since there can be substantial differences between the two. Finally, a brief comparison of simulation and experimental results under different operating conditions was conducted, with reasonable agreement, given the wide dispersion of the experimental data.

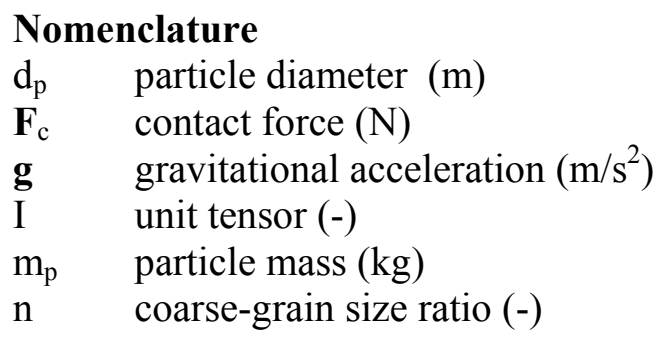




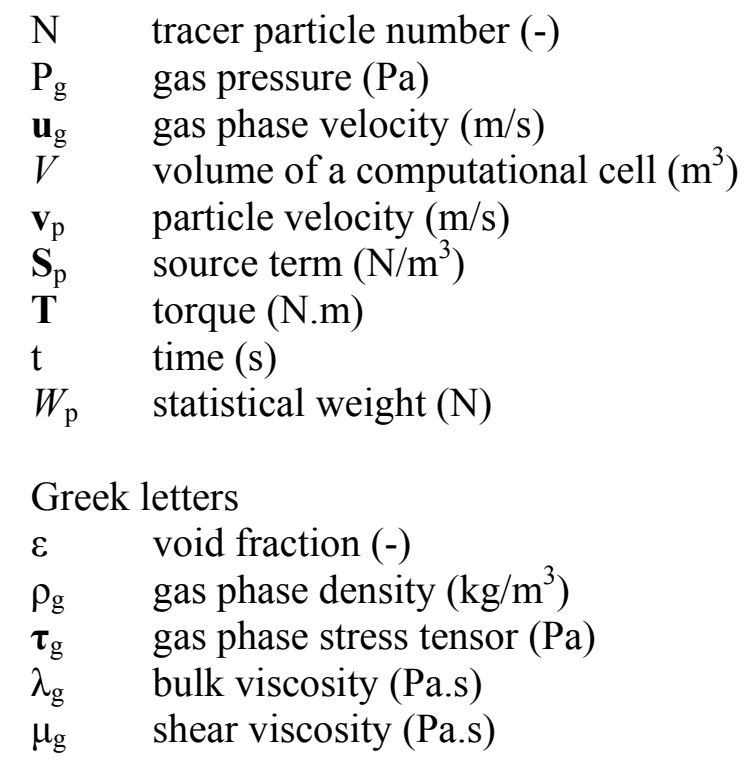

\section{Acknowledgement}

This technical paper was produced in support of the National Energy Technology Laboratory's ongoing research in advanced numerical simulation of multiphase flow under RES contract DE-FE0004000. This research was also supported in part by an appointment to the National Energy Technology Laboratory Research Participation Program, sponsored by DOE and administered by the Oak Ridge Institute for Science and Education. Financial support from the Natural Sciences and Engineering Research Council of Canada (NSERC) is also gratefully acknowledged.

\section{Disclaimer}

This paper was prepared as an account of work sponsored by an agency of the United States Government. Neither the United States Government nor any agency thereof, nor any of their employees, makes any warranty, express or implied, or assumes any legal liability or responsibility for the accuracy, completeness, or usefulness of any information, apparatus, product, or process disclosed, or represents that its use would not infringe privately owned rights. Reference herein to any specific commercial product, process, or service by trade name, trademark, manufacturer, or otherwise does not necessarily constitute or imply its endorsement, recommendation, or favoring by the United States Government or any agency thereof. The views and opinions of authors expressed herein do not necessarily state or reflect those of the United States Government or any agency thereof.

\section{References}

Alobaid, F.; Epple, B. Improvement, validation and application of CFD/DEM Model to Dense Gas-solid Flow in a Fluidized Bed. Particuology 2013, 11 (5), 514-526.

Bi, H.T., Zhou, J,, Qin, S.Z., Grace, J.R. Annnular wall layer thickness in circulating fluidized bed risers, Can.J.Chem.Eng., 1996, 74, 811-814.

Chaouki, J.; Larachi, F.; Dudukovié, M. Radioactive particle tracking in multiphase 
reactors: principles and applications. Non-invasive Monit. Multiph. Flows 1997, 335.

Cundall P. A., and Strack O.D.L. A discrete numerical model for granular assemblies, Geotechnique, 1979, 29: 47-65.

Dietiker, J. F. Multiphase Flow with Interphase eXchanges: Cartesian Grid User Guide; 2015.

Dietiker, J. F.; Guenther, C.; Syamlal, M. A Cartesian cut cell method for gas/solids flow. In AIChE annual meeting; Nashville, TN, 2009.

Dubrawski, K.; Tebianian, S.; Bi, H.T.; Chaouki, J.; Ellis, N.; Gerspacher, R.; Jafari, R.; Kantzas, A.; Lim, C.J.; Patience, G.S.; Pugsley, T.; Qi, M.Z.; Zhu, J.X.; Grace, J.R. Traveling column for comparison of invasive and non-invasive fluidization voidage measurement techniques. Powder Technol. 2013, 235, 203-220.

Elghobashi, S. On Predicting particle-laden turbulent flows. Appl. Sci. Res. 1994, 52 (4), 309-329.

Elghobashi, S. An updated classification map of particle-laden turbulent flows. In IUTAM Symposium on Computational Approaches to Multiphase Flow; Springer Netherlands: Dordrecht, 2006; pp 3-10.

Garg, R.; Galvin, J.; Li, T.; Pannala, S. Open-source MFIX-DEM software for gas-solids flows: Part I-Verification Studies. Powder Technol. 2012, 220, 122-137.

Gopalakrishnan, P.; Tafti, D. Development of parallel DEM for the open source code MFIX, Powder Technol. 2013, 235, 33-41.

Karri, R. S. B; Werther, J. Gas distributor and plenum design in fluidized beds, in Handbook of fluidization and fluid-particle systems, eds. Wen-Ching Yang, 2003, Marcel Dekker Inc, New York.

Kirkpatrick, M. P.; Armfield, S. W.; Kent, J. H. A Representation of curved boundaries for the solution of the Navier-Stokes equations on a staggered three-dimensional Cartesian grid. J. Comput. Phys. 2003, 184 (1), 1-36.

Leadbeater, T. W.; Parker, D. J.; Gargiuli, J. Positron imaging systems for studying particulate, granular and multiphase flows. Particuology 2012, 10 (2), 146-153.

Li, T.; Garg, R.; Galvin, J.; Pannala, S. Open-source MFIX-DEM software for gas-solids Flows: Part II - Validation Studies. Powder Technol. 2012, 220, 138-150.

Li, T. Validation of a 2.5D CFD model for cylindrical gas-solids fluidized beds, Powder Technol. 2015, 286, 817-827.

Liu, H.; Tafti, D.K.; Li, T. Hybrid parallelism in MFIX CFD-DEM using OpenMP, Powder Technol. 2014, 259, 22-29.

Lu, L.; Xu, J.; Ge, W.; Yue, Y.; Liu, X.; Li, J. EMMS-based discrete particle method (EMMS-DPM) for simulation of gas-solid flows. Chem. Eng. Sci. 2014, 120, 6787.

Lu, L.; Xu, J.; Ge, W.; Gao, G.; Jiang, Y.; Zhao, M.; Liu, X.; Li, J. Computer virtual experiment on fluidized beds using a coarse-grained discrete particle method- 
EMMS-DPM. Chem. Eng. Sci. 2016, 155, 314-337.

Lu, L.; Xu, Y.; Li, T.; Benyahia, S. Assessment of different coarse graining strategies to simulate polydisperse gas-solids flow. Submitt. to Chem. Eng. Sci. 2017.

Patience, G. S.; Chaouki, J. Gas Phase Hydrodynamics in the riser of a circulating fluidized bed. Chem. Eng. Sci. 1993, 48 (18), 3195-3205.

Sakai, M.; Abe, M.; Shigeto, Y.; Mizutani, S.; Takahashi, H.; Viré, A.; Percival, J.R.; Xiang, J.; Pain, C.C. Verification and validation of a coarse grain model of the DEM in a bubbling fluidized bed, Chem. Eng. J. 2014, 244, 33-43.

Syamlal, M.; Rogers, W.; O’brien, T. J. MFIX Documentation: Theory Guide; 1993.

Tebianian, S. Comparison of alternative advanced experimental techniques for measurement of hydrodynamic characteristics of gas-fluidized beds, University of British Columbia, 2015.

Tebianian, S.; Dubrawski, K.; Ellis, N.; Cocco, R. A.; Hays, R.; Karri, S. B. R.; Leadbeater, T. W.; Parker, D. J.; Chaouki, J.; Jafari, R.; Garcia-Trinanes, P.; Seville, J.P.; Grace, J.R. Investigation of particle velocity in FCC gas-fluidized beds based on different measurement techniques. Chem. Eng. Sci. 2015a, 127, $310-322$.

Tebianian, S.; Ellis, N.; Lettieri, P.; Grace, J. R. X-Ray Imaging for flow characterization and investigation of invasive probe interference in travelling fluidized bed. Chem. Eng. Res. Des. 2015b, 104, 191-202.

Tebianian, S.; Dubrawski, K.; Ellis, N.; Cocco, R. A.; Hays, R.; Karri, S. B. R.; Leadbeater, T. W.; Parker, D. J.; Chaouki, J.; Jafari, R.; Garcia-Trinanes, P.; Seville, J.P.; Grace, J.R. Comparison of particle velocity measurement techniques in a fluidized bed operating in the square-nosed slugging flow regime. Powder Technol. 2016a, 296, 45-52.

Tebianian, S.; Dubrawski, K.; Ellis, N.; Cocco, R. A.; Hays, R.; Karri, S. B. R.; Leadbeater, T. W.; Parker, D. J.; Chaouki, J.; Jafari, R. Solids flux measurements via alternate techniques in a gas-fluidized bed. Chem. Eng. J. 2016b, 306, 306321.

van der Hoef, M. A.; Ye, M.; van Sint Annaland, M.; Andrews, A. T.; Sundaresan, S.; Kuipers, J. A. M. Multiscale modeling of gas-fluidized beds. Adv. Chem. Eng. 2006, 31, 65-149.

Verma, V.K.; Deen, N.G.; Padding, J.T.; Kuipers, J.A.M. Two-fluid modeling of three dimensional cylindrical gas-solid fluidized beds using the kinetic theory of granular flow, Chem. Eng. Sci. 2013, 102, 227-245.

Verma, V.; Li, T.; De Wilde, J. Coarse-grained discrete particle simulations of particle segregation in rotating fluidized beds in vortex chambers. Powder Technol. 2017, $318,282-292$.

Xu, Y.; Padding, J. T.; van der Hoef, M. A.; Kuipers, J. A. M. Detailed numerical simulation of an intruder impacting on a granular bed using a hybrid discrete particle and immersed boundary (DP-IB) method. Chem. Eng. Sci. 2013, 104, 
201-207.

Xu, Y.; Padding, J. T.; Kuipers, J. A. M. Numerical investigation of the vertical plunging force of a spherical intruder into a prefluidized granular bed. Phys. Rev. E - Stat. Nonlinear, Soft Matter Phys. 2014, 90 (6).

Xu, Y.; Li, T.; Musser, J.; Liu, X.; Xu, G.; Rogers, W. A. CFD-DEM modeling the effect of column size and bed height on minimum fluidization velocity in micro fluidized beds with Geldart B particles. Powder Technol. 2017a, 318.

Xu, Y.; Musser, J.; Li, T.; Gopalan, B.; Panday, R.; Tucker, J.; Breault, G.; Clarke, M. A.; Rogers, W. Numerical simulation and experimental study of the gas-solid flow behavior inside a full-loop circulating fluidized bed: Evaluation of different drag models. Ind. Eng. Chem. Res. 2017b.

Xu, Y.; Musser, J.; Li, T.; Padding, J. T.; Rogers, W. A. Particles climbing along a vertically vibrating tube: numerical simulation using the Discrete Element Method (DEM). Powder Technol. 2017c, 320, 304-312. 